\title{
How helpful is NHS Direct? Postal survey of callers
}

\author{
A O'Cathain, J F Munro,J P Nicholl, E Knowles
}

NHS Direct, the new 24 hour telephone advice line staffed by nurses, was established to "provide easier and faster information for people about health, illness and the NHS so that they are better able to care for themselves and their families." In March 1998, three first wave sites started in Lancashire, Milton Keynes, and Northumbria. As part of an extensive evaluation of this new service, ${ }^{2}$ we surveyed callers to determine how helpful they found the advice offered.

\section{Participants, methods, and results}

With approval of local ethics committees, we sampled 350 consecutive callers at each site during one week in September 1998, giving a total of 1050 callers. The sampled period covered Saturday to Wednesday. A questionnaire about callers' experiences and views of NHS Direct was posted within one week of the call, with up to two reminders. A total of 719 questionnaires were completed by callers and 32 were not received by callers, giving a response rate of $71 \%(719 / 1018)$ with rates of $66 \%, 65 \%$, and $81 \%$ for the individual sites; $81 \%(579 / 719)$ of respondents made written comments. The median age of respondents was 35 years (interquartile range 29 to 47 ) and $80 \%(567 / 711)$ were women. Most (684, 95\%) said that they had spoken to a nurse for advice. Of these 684 , only 673 gave details of the advice: eight $(1 \%)$ reported being diverted to emergency services, $138(21 \%)$ were advised to contact accident and emergency, $136(20 \%)$ a general practitioner immediately, $85(13 \%)$ a general practitioner in the next 24 hours, $80(12 \%)$ a general practitioner at the next opportunity, $50(7 \%)$ another service, and 176 $(26 \%)$ to self treat.

The table shows that most respondents who received advice from a nurse found it very or quite helpful (643 (95\%); 95\% confidence interval 93\% to $97 \%$ ) and most followed all of the advice given by the nurse (566 (85\%); $82 \%$ to $88 \%)$. The most common reason given for finding the advice helpful was that it

\begin{tabular}{|c|c|}
\hline \multicolumn{2}{|c|}{ Callers' views of and response to advice offered by nurse } \\
\hline & $\begin{array}{l}\text { No }(\%) \text { of } \\
\text { respondents }\end{array}$ \\
\hline \multicolumn{2}{|l|}{ Helpfulness of nurse advice ${ }^{\star}$ : } \\
\hline Very helpful & $511(76)$ \\
\hline Quite helpful & $132(20)$ \\
\hline Not helpful & $31(5)$ \\
\hline \multicolumn{2}{|l|}{ Reason why advice was helpfult: } \\
\hline Reassurance & $425(66)$ \\
\hline Help to contact the right service & $226(35)$ \\
\hline Learnt to deal with problem by self & $145(23)$ \\
\hline Avoided contacting a service & $91(14)$ \\
\hline Learnt to prevent problem in future & $31(5)$ \\
\hline \multicolumn{2}{|l|}{ Acted on adviceł: } \\
\hline Yes, all of it & $566(85)$ \\
\hline Yes, some of it & $84(13)$ \\
\hline No & $18(3)$ \\
\hline
\end{tabular}

${ }^{\star}$ Question completed by 674 of 684 callers receiving nurse advice. †Multiple response question.

‡Question completed by 668 of 684 callers receiving nurse advice. was reassuring. Of the 579 written comments, 173 mentioned reassurance: 134 (77\%) gained reassurance from the advice offered or the attitude of the nurse and others from knowing the service was there, from receiving confirmation that they needed to use a health service, or that they were right to treat themselves.

Thirty one callers did not find the nurse advice helpful. Eleven commented that they had wanted more advice about their problem rather than referral to a service, 10 disagreed with the place or urgency of referral; and 10 gave various other reasons. Other respondents commented on the friendliness of the staff (256), the helpfulness of the advice (200), the service overall (166), the promptness of the service (113), avoiding "wasting the time of" or "bothering" services such as general practice (65), and not being made to feel they were wasting the time of the service (52).

\section{Comment}

We found that the advice offered by nurses at the first wave NHS Direct sites was well received by most callers, achieving levels of satisfaction comparable with other telephone advice services. ${ }^{3}$ Given the $71 \%$ response rate, non-response bias must be considered. In the worst case, if all non-respondents were assumed to find the advice unhelpful, the percentage finding the advice helpful would be $63 \%(643 / 1018)$. Many callers found the advice helpful because it offered reassurance, which has been noted as a key benefit of general practice telephone consultations during surgery hours ${ }^{4}$ and as an important aspect of nursing practice. ${ }^{5}$ Further qualitative research could help us to understand callers' need for reassurance and the nature of the reassurance gained. These results raise the question of the role which the NHS can and should play in meeting this apparent need for reassurance.

Contributors: AO'C designed the questionnaire, coordinated data collection, analysed the data, wrote the paper, and acts as guarantor for the paper. JFM and JPN designed the study and participated in the design of the questionnaire, interpretation of the data, and writing the paper. EK participated in the design of the questionnaire, interpretation of the data, and writing the paper. April Dagnell undertook data administration. Evan Davies, Joanne Beach, and Andrea Nicholson at the NHS Direct sites distributed the questionnaires.

Funding: Department of Health. The views expressed here are those of the authors and not necessarily those of the Department of Health.

Competing interests: None declared.

1 Department of Health. The new NHS. London: Stationery Office, 1997. (Cmd 3807.)

2 Munro J, Nicholl J, O'Cathain A, Knowles E. Evaluation of NHS Direct first wave sites. First interim report to the Department of Health. Sheffield: Medical Care Research Unit, University of Sheffield, 1998.

3 Poole SR, Schmitt BD, Carruth T, Peterson-Smith A, Slusarski M. After-hours telephone coverage: the application of an area-wide telephone triage and advice system for paediatric practices. Pediatrics 1993;92:670-9.

4 Nagle JP, McMahon K, Barbour M, Allen D. Evaluation of the use and usefulness of telephone consultations in one general practice. $\mathrm{Br} \mathrm{J} \mathrm{Gen}$ Pract 1992;42:190-3.

5 Fareed A. The experience of reassurance: patients' perspectives. $J$ Adv Nurs 1996;23:272-9.

(Accepted 24 March 2000)
Medical Care Research Unit, School of Health and Related Research, Sheffield S1 4DA A O'Cathain research fellow J F Munro clinical lecturer $\mathrm{J}$ P Nicholl professor E Knowles research associate Correspondence to: A O'Cathain a.ocathain@ sheffield.ac.uk

BMJ 2000;320:1035

(B)

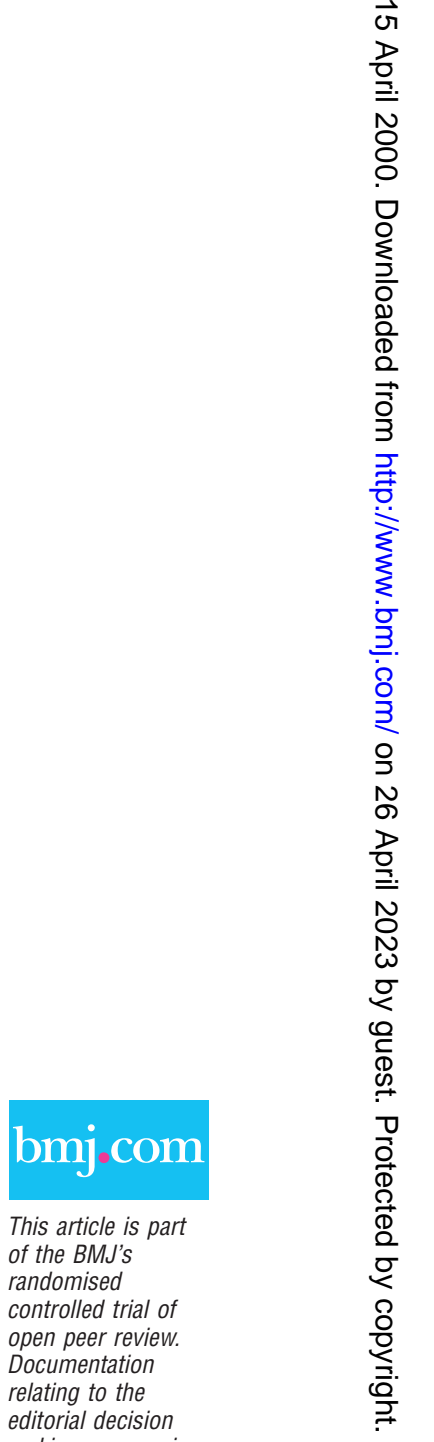
making process is available on the BMJ's website 